\title{
Towards a comprehensive theory of culturally constructed humour
}

\author{
Sajjad Kianbakht \\ RMIT University, Melbourne, Australia \\ Sajjad.kianbakht@rmit.edu.au
}

\begin{abstract}
In the present research, we discuss Humour Studies within Linguistics, focusing mainly on linguistic theories of humour including the Semantic Script Theory of Humour (SSTH; Raskin 1985), and the General Theory of Verbal Humour (GTVH; Attardo 1994, 2017b). The study demonstrates different types of cultural conceptualisations (Sharifian 2017a, 2017b) that the interlocutors draw upon, such as cultural categories, cultural metaphors, and cultural schemas to create humour, and we argue that the General Theory of Verbal Humour does not account for culturally-constructed verbal humour. Hence, we argue that it is necessary to fill this gap in the most prevailing theory of verbal humour, the General Theory of Verbal Humour, by demonstrating how cultural conceptualisations must be considered in identifying and analysing instantiations of humour, in moving towards a comprehensive theory of culturally constructed humour.
\end{abstract}

Keywords: humour, General Theory of Verbal Humour, cultural conceptualisations.

\section{Introduction}

Humour is deeply embedded in the specific cultural context in which it is produced, and it is a part of everyday language use, and a component of many literary works and art in any linguistic community. The way people use humour shows not only their ability to play with language but also indicates the shared beliefs and culture common to the speakers of a language, and their communicative norms and style (Stankic, 2017). However, as Attardo, the editor of Encyclopedia of Humour Studies, plausibly argues, in current humour theories, "the interplay of ideologies, systems of beliefs ... are largely unexplored" (Attardo 2017b: 96). In a similar vein, several other scholars, such as Chlopicki \& Brzozowska (2017) in the book Humorous Discourse, have 
advocated this point of view. While discussing "problems of humour research," they lucidly emphasised:

the need for the theoretical and empirical studies of humorous discourse and at the same time emphasized multiple extra-linguistic, contextual, and cultural factors which humour scholars have to take into account in order to provide an exhaustive description of the functioning of humorous discourse - a large step for linguists (Chlopicki \& Brzozowska 2017: 4).

Hence, on the basis of these considerations, we focus on the interplay of cultural conceptualisations that interlocutors draw upon in creating humorous discourse to contribute to this current ongoing debate in Linguistics and Humour Studies.

In the following sections, therefore, we will discuss the current frameworks of Humour Studies and humour research within Linguistics, specifically linguistic theories of humour including the Semantic Script Theory of Humour (SSTH; Raskin 1985), and the General Theory of Verbal Humour (GTVH; Attardo 1994, 2017b). Subsequently, Cultural Linguistics, cultural conceptualisations (Sharifian 2017a, 2017b), their relevance to humour theories, and the crucial role they play in a comprehensive theory of verbal humour will be explicated.

\section{Humour studies within linguistics}

Humour in its current status is a multidisciplinary area of research (Attardo 2017c; Attardo \& Raskin 2017), and scholars in many different fields of research such as Psychology, Philosophy, Sociology, and Linguistics have always ventured into it from their disciplinary field (Raskin, 2017). In Humour Studies, several theories of humour attempt to explain why we laugh and what humour means. However, despite all the theories and studies on humour, as Berger argues (1987: 2), it has "remained a puzzle to the best minds we have produced." That is to say, as Olin in the Questions for a Theory of Humour (2016) argues, the works of Aristotle, Plato, Kant, Bergson, Freud, Bateson and other contemporary scholars of humour research such as Attardo and Raskin could not present an overarching explanation of humour as a phenomenon, and indeed, as Berger emphasises (2017), the existing frameworks of humour have limitations. However, each of them has contributed to our understanding of this complex phenomenon (cf. Chovanec \& Tsakona 2018).

Studies on humour, according to Berger (2014) in the Encyclopedia of Humour Studies, are generally divided into three branches and research paradigms, which explain why we laugh and why we find something funny: (1) the Psychological-relief theory of humour, referring primarily to Freud's ideas; (2) the Philosophical-superiority theory of humour, which has its roots in Antiquity in Plato and Aristotle's works and which focuses on the asymmetric relationship between interlocutors; and (3) the Incongruity theory of humour, dealing with the linguistic realm of humour focusing on Script Opposition (see section 2.1), which is considered as the origin of linguistic theories of humour such as the Semantic Script Theory of Humour and the General Theory of Verbal Humour frameworks (Attardo 2014). 
The incongruity theory of humour is the most influential framework for the study of humour (Mulder \& Nijholt 2002: 4). It deals with the linguistic realm of humour when two disparate notions turn out to have a surprising relationship, which activates witty thought and humour (Ashouri Talooki 2017). In other words, the theory refers to the humour that derives, as Berger (1987: 8) argues, from "a difference between what one expects and what one gets, a lack of consistency and harmony" (Berger 1987: 8) which is labelled as incongruity (Ashouri Talooki, 2017). Morreall (1997) explains that the use of wordplay and puns, which carries a mismatch between what the audience expect and what they read (Morreall 1997; see also Ashouri Talooki 2017), is one of the fundamental features of this theory that deals with the linguistic realm of humour research. The theory explains how jokes are structured, and even though it does not account for the influence of surrounding factors, such as the culture-reliant context, as Ritchie (2004), Martin (2007) and Olin (2016) argue, it is widely applied by scholars who study humour (Ashouri Talooki 2017). The incongruity theory leads us to the Semantic Script Theory of Humour and the General Theory of Verbal Humour frameworks.

Therefore, the present research will provide a review of the Semantic Script Theory of Humour (Raskin 1985), and the General Theory of Verbal Humour (Attardo \& Raskin 1991; Attardo 1997, 2003, 2008), which are indebted, to a very great extent, to Raskin's (1985) and Attardo's attempts to describe the humorous mechanism from the semantic (1997; Attardo \& Raskin 1991), and subsequently from the pragmatic aspects (Attardo 2002, 2003, 2014, 2017c; Attardo \& Raskin 2017; Raskin 2008, 2017). These two most influential linguistic theories of humour, which constitute the foundations of the existing approaches to humour, and which are especially important for moving towards a comprehensive theory of culturally constructed humour, will be discussed in the following sections.

\subsection{Semantic Script Theory of Humour}

Raskin introduced a full-fledged account of the Semantic Script Theory of Humour in his seminal work Semantic Mechanisms of Humor (1985). The theory is based on two key features, stating that each sequence of humour can be interpreted in two different opposing ways. Raskin labelled these two conditions or prerequisites of humorous texts as "overlapping," to mean embracing two interpretations of the same text at the same time; and "opposing," meaning that these two overlapping interpretations could be categorised opposites (Raskin 1985: 99). In the following sections, scripts, overlapping and opposing will be discussed; they are the focal points of the Semantic Script Theory of Humour and the basis of the subsequent linguistic theories of humour, such as the General Theory of Verbal Humour (Attardo \& Raskin 1991; Attardo 2002, 2003, 2008), among others.

\subsubsection{Scripts}

Script is defined as "a large chunk of semantic information surrounding the word or evoked by it" (Raskin 1985: 81; see also Attardo 1994). Attardo argues that "it is a cognitive structure internalised by the speaker which provides the speaker with information on how things are done, organised, etc." (Attardo 1994: 199). For example, a restaurant script conjures up a sequence of related scripts in the mind of the audience, such as driving up to the restaurant, being seated, reading the menu, ordering food and so on (Attardo 1994). 


\subsubsection{Overlapping}

Overlapping occurs when "stretches of text are compatible with more than one reading" (Attardo 1994: 203). In other words, when a stretch of text matches with more than one interpretation, it is said to have an overlapping condition. An example of this is "a text describing someone getting up, fixing breakfast, leaving the house, etc. These events could fit the script for 'Go to Work' but also for 'Go on a Fishing Trip' hence the stretch of text would be compatible with both scripts" (Attardo 1994: 203). According to the Semantic Script Theory of Humour, a text with overlapping scripts requires another condition to be considered as humorous, which leads to the next core value of the Semantic Script Theory of Humour: the opposing condition.

\subsubsection{Opposing}

The opposing condition is satisfied when the two overlapping scripts also oppose each other in a certain way. Raskin (1985: 127) offers three sets of opposing conditions that can appear in a humorous text: "normal/abnormal, actual/non-actual and possible/impossible" with one underlying basic opposition set: "real/unreal" situations in the texts. Raskin supplements these three sets of oppositions with five more concrete, real-life opposing situations: "good/bad, life/death, obscene/non-obscene, money/no money, and high/low stature" (1985: 127). In a nutshell, the centrepiece of Raskin's Semantic Script Theory of Humour (1985) is recapitulated by Attardo's statement: "if a text is compatible fully or in part with two scripts, and the two scripts happen to be opposed to each other, then, and only then, will the text be classified as "funny" by the SSTH" (Attardo 1994: 205).

\subsection{General Theory of Verbal Humour (GTVH)}

Attardo \& Raskin (1991; see also Attardo 2002, 2003, 2008) developed a list of parameters, called Knowledge Resources, that contribute to the funniness of the verbal humour with the Script Opposition as the focal point and the central requirement of humour. The Script Opposition accounts for the opposition between two scripts considered contradictory and overlapping in a certain way. These Six Knowledge Resources are Script Opposition, Logical Mechanism, Situation, Target, Narrative Strategy and Language. This theory proposes that verbal humour can be analysed and described in light of these parameters, which are organised in a hierarchical structure. These Knowledge Resources each contributes to the humorous effect of the instances of humour with the Script Opposition at the top of the hierarchy as its most determining parameter. The following figure taken from Attardo (2002: 183) represents the hierarchical structure of these Knowledge Resources in the General Theory of Verbal Humour: 


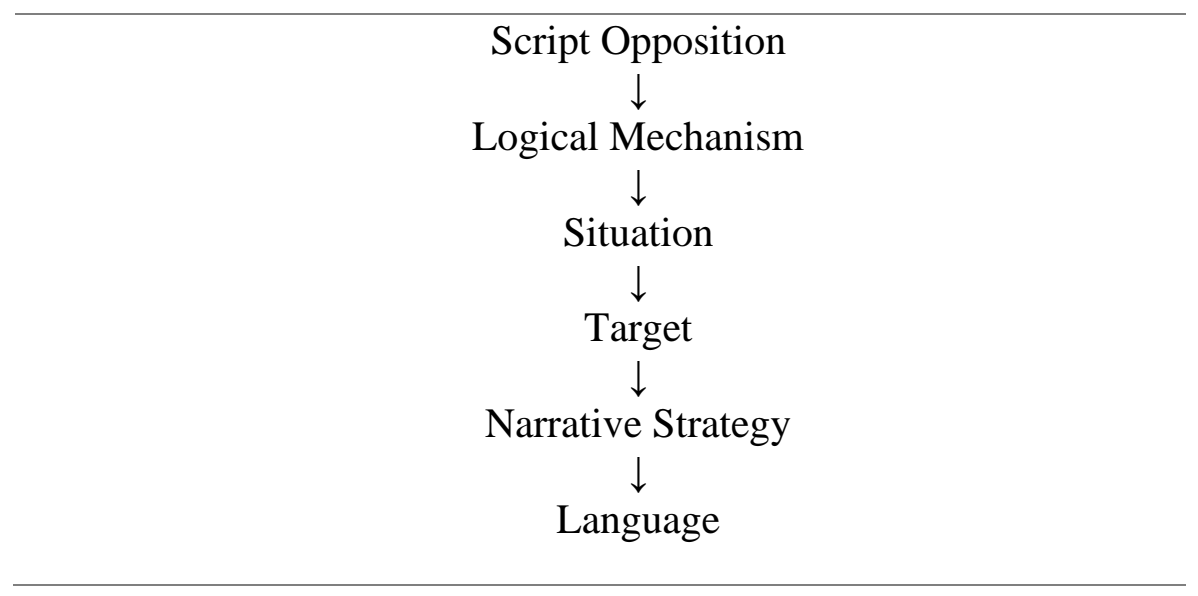

Figure 1: The Hierarchical Structure of KRs (Attardo 2002: 183)

The following paragraphs discuss the General Theory of Verbal Humour's Knowledge Resources.

\subsubsection{Script opposition (SO)}

This Knowledge Resource focuses on the Script Opposition parameter proposed by Raskin's SSTH (see section 2.1). It implies an opposition between two scripts or schemas considered contradictory and overlapping in a certain way, which causes incongruity in the humorous utterance.

\subsubsection{Logical mechanism (LM)}

The Logical Mechanism is a parameter that resolves the incongruity, which is evoked by the humorous text in the mind of the reader. In other words, it enables the reader to move beyond the Script Opposition existing in the humorous text and to decide which script is intended. Attardo (1994) puts it in this way: "the Logical Mechanism is the parameter that accounts for the way in which the two senses (scripts) in the joke are brought together" (for more details see Raskin 1985: 103). Logical Mechanisms can range from juxtapositions to false analogies, or figure-ground reversals. A list of LMs is summarised in the following table taken from Attardo et al. (2002: 18): 
Table 1: Attardo et al.'s list of LMs (2002: 18)

\begin{tabular}{c|c|c}
\hline Role-Reversals & Role Exchanges & Potency Mappings \\
Vacuous Reversal & Juxtaposition & Chiasmus \\
Garden-Path & Figure-Ground Reversal & Faulty Reasoning \\
Almost Situations & Analogy & Self-Undermining \\
Inferring & Reasoning from False Premises & Missing Link \\
Consequences & Parallelism & Implicit Parallelism \\
Coincidence & Ignoring The Obvious & False Analogy \\
Proportion & Field Restriction & Cratylism \\
Exaggeration & Vicious Circle & Referential \\
Meta-Humor & & Ambiguity \\
\hline
\end{tabular}

\subsubsection{Situation (SI)}

Attardo (2002) explains that "any joke must be 'about something' (changing a light bulb, crossing the road, playing golf, etc.)" (Attardo 2002: 179). The Situation includes objects, activities, and instruments of a humorous instance. Attardo (2002: 179) further explains a stenography Situation in a joke through the following example: "Can you write shorthand? Yes, but it takes me longer."

\subsubsection{Target (TA)}

The Target is the victim of the joke or using Attardo \& Raskin's term, the butt of the joke. The Target of the joke can conjure up, in the mind of the reader, the names of groups or individuals as well as ethnic minorities with humorous stereotypes. Consider the following joke that targets Poles, as stereotypical targets for jokes in America taken from Krikmann (2006: 37): "How many Poles does it take to empty the ashtray of a car? Ten, to turn the car upside down."

\subsubsection{Narrative Strategy (NS)}

The Narrative Strategy can be seen as a "rephrasing of what is known in literary theory under the name genre" (Attardo 1994: 224). It is responsible for the syntactic-semantic organisation of a joke. In other words, a joke has to be narrated in some form of an idiom or a slang, a proverb or a simple narrative, a dialogue or a riddle.

\subsubsection{Language (LA)}

Language is the parameter that accounts for the linguistic instantiation of humour. The Language strategy "contains all the information necessary for the verbalisation of a text" (Attardo 1994: 223). Overall, the General Theory of Verbal Humour and its Knowledge Resources form the basis of the linguistic frameworks of humour that have been applied by different scholars to investigate the complexities of humour analysis across different languages and cultures. The present study intends to contribute to this ongoing research. 
For illustration purposes, we present here the application of the GTVH to the following instance of humour: "The Doctor's Wife Joke," taken from Attardo (2008) and Raskin (1985: 117127) as an aid in understanding how the GTVH works in identifying the instances of humour:

“A: 'Is the doctor at home?' the patient asked in his bronchial whisper.

B: 'No,' the doctor's young and pretty wife whispered in reply. 'Come right in'" (Raskin 1985: 117- 127; see also Attardo 2008).

A semantic interpretation of this example can be loosely read as: a patient, who has been previously treated for some disease, asked about the presence of a doctor at the doctor's place of residence, with the aim of being treated for an illness that is evidenced by the patient's whispering (Raskin 1985: 117- 127; see also Attardo 2008). The doctor's wife, who is a young and pretty woman, whispers that the doctor is not at home, and invites him to enter the house. Here, the target readership is faced with a dilemma: if the aim of the man's question is the desire to be cured for his illness, why is the doctor's wife asking him to come into the house? The doctor is not at home, and the Script for "DOCTOR" necessitates a doctor's physical presence for examination and curing the disease! The Situation of this example leads the audience to start looking for another Opposing Script to make sense of the story (Raskin 1985: 125), i.e., an alternative evaluation of the story. The reader will thus sit back and re-interpret the story. The wife's gender and her explanation will be taken into consideration, as well as the absence of the doctor (her husband). This interpretation will conjure up the "LOVER" Script in the mind of the audience, which allows the activation of the Logical Mechanism that an improper relationship is going on without the knowledge of the legitimate partner (Raskin 1985: 117- 127; see also Attardo 2008). In view of the "LOVER" Script, the behaviour of the doctor's wife's becomes meaningful; i.e. the doctor's wife misuses her husband's absence for having an affair with another man. The example is, therefore, found to be compatible with two Opposing Scripts ("DOCTOR" vs. "LOVER"), which are opposing each other based on "SEX/NO SEX." Thus, the example satisfies the requirements of the GTVH (SO: doctor vs. lover; LM: an adulterous relation be acted upon without the knowledge of the lawful spouse; SI: meeting the doctor's wife; TA: improper relationships; NS: conversation; LA: English text) and therefore, is assessed as humorous (Raskin 1985: 117- 127; see also Attardo 2008).

Attardo, in his (2001) book, Humorous Texts: A Semantic and Pragmatic Analysis presents a methodology to extend the analysis of the GTVH to all types of texts, regardless of their length. Since the introduction of the Semantic Script Theory of Humour (SSTH; Raskin 1985) and its later version, the General Theory of Verbal Humour (GTVH; Attardo 1994), there have been several attempts by different scholars to apply the theory to longer humorous texts (see, among others, Ermida 2008; Chlopicki 2017). Ermida (2008) offers a linguistic analysis of how humour works in short stories. Her main argument was that the existing humour theories, specifically, Raskin and Attardo's script-based theory and Giora's cognitive approach, were devised for the analysis of jokes in isolation, and therefore have limited applicability to other kinds of humorous texts, such as short stories (Ermida, 2008). Drawing on pragmatics, she applied the most influential linguistic theories of humour, Raskin's principle of script opposition (1985) and Giora's notion of marked informativeness (1991) in a novel way to humorous short stories. She argued that a linear analysis (cf. Attardo 2001), is not sufficient to describe the humorous nature of short stories, and proposed a supra-sequential approach, arguing that the text is not a succession of autonomous joke-like 
structures (Ermida 2008: 111), and believed in a hierarchical organisation of the texts. Although Ermida's (2008) interdisciplinary, still linguistic-oriented approach is a unique contribution to the study of humour and humorous discourse analysis dealing with constructing literary narratives, she did not delve into the cultural conceptualisations underlying humour (see section 3), which are addressed here. In the present research, we offer a systematic analytical framework for an indepth analysis of verbal humour - despite its notorious elusiveness as an analytical concept in humour research.

In a similar vein, Chlopicki (2017), in "Humour and narrative", provided an overview of research on humour in narratives and outlined some problematic areas that have been at the core of the scholarly debate on humour, the connections between humour and narrative. He proposed an analysis of perceptual imagery and character frames in humorous short stories, proposing that both elements would supplement the existing script-based humour analyses. He demonstrated how text-specific frames are applied in narrative humour analysis, and how "competing, but not incompatible linguistic paradigms have expanded into the area of narrative humour research." Chlopicki's (2017) study was an advancement in the area of humour in narratives, although we argue that the cultural conceptualisations that are crucial for humour analysis have remained, to date, unexplored, in humour studies.

Attardo, in several overviews (2001, 2017a), discusses the works of scholars who have contributed to extending the analysis of the GTVH to all types of texts, regardless of their length. He divided the contributors into two overarching groups: (a) expansionists and (b) revisionists. On the one hand, expansionists propose that jokes in the GTVH-sense share essential characteristics with all humorous texts, and therefore, it can be applied to all types (Attardo 1994, 2001). On the other hand, the revisionists consider the theory as a theory of jokes as a text-type, and therefore, propose revisions to the theory, intending to make it applicable to other text-types (Attardo 1994, 2001). However, in the present research, we contend that downplaying humour analysis to just linguistic formalisms, such as the ones proposed in the Semantic Script Theory of Humour and the General Theory of Verbal Humour is inadequate, as these linguistic-oriented approaches need to be reinforced, at underlying conceptual layers of the analysis (see section 6), by a cutting-edge, recently developed framework, such as Cultural Linguistics' cultural conceptualisations analytical framework (see section 3), to adequately account for this complex culture-reliant phenomenon. We argue that these cultural conceptualisations underlying humour and its analysis are far removed from the scope of the Semantic Script Theory of Humour and the General Theory of Verbal Humour. Therefore, due to the limited applicability of these dominant linguistic-oriented theories, we contend that an in-depth analysis of verbal humour can be best achieved by adopting a new framework: Cultural Linguistics and it conceptual, analytical units, such as cultural conceptualisations (i.e. cultural schemas, cultural categories, cultural metaphors), with the GTVH as its "independent" component. This necessitates paying closer attention to the conceptual aspects of humour, especially the conceptual dimensions that are culturally constructed. All in all, we argue that it is no longer possible to ignore how crucial cultural conceptualisations and their analysis have become for Humour Studies (cf. Brekhus \& Ignatow 2019; Strandell 2019; Zabalbeascoa 2019), which calls upon further research into the relationship between language, cultural conceptualisations and cognition in humour research (cf. Sharifian 2018). This viewpoint is supported by several other scholars, and it is in line with the current shift towards conceptual analysis in language and cultural studies (Brekhus \& Ignatow 2019; Strandell 2019). 


\section{Cultural linguistics and humour studies}

\subsection{The role of cultural conceptualisations in linguistic theories of humour}

Cultural Linguistics is a current, multidisciplinary field of research developed by the anthropological linguistics professor, Farzad Sharifian (2017a, 2017b) from Monash University. It explores the relationship between language and cultural conceptualisations (see also Sharifian 2003, 2011, 2012, 2015). "Cultural conceptualisations are the tools Cultural Linguistics uses to study aspects of cultural cognition and its instantiation in language" (Peeters 2016: 1). Sharifian explains that Cultural Linguistics (a) assumes that features of human languages communicate and embody conceptualisations, and (b) focuses on the analysis of conceptualisations that are culturally constructed $(2011,2012,2017 \mathrm{a}, 2017 \mathrm{~b})$. This is highly relevant to this research, since culturally constructed elements such as humour are subject to significant influence from cultural contexts in which they are used. Sharifian (2011) further maintains that the advent of this multidisciplinary area of research "has shifted focus from the relationship of individual cognition and language as highlighted in the cognitive approaches to language, to the relationship between language, cultural conceptualisation and cognition" (Sharifian 2011: 3).

For Cultural Linguistics "language is a cultural form, and that conceptualisations underlying language and language use are largely formed by cultural systems" (Yu 2007: 65). Cultural conceptualisation as a central concept is used in the present research to indicate "patterns of distributed knowledge across the cultural group" (Sharifian 2011: 3), which also covers Strauss and Quinn's (1997) schematisation and schemas (see section 3.1.3.), and Lakoff's (1987) categories and metaphors (see sections 3.1.1. \& 3.1.2.), which are of particular importance for the analysis of humour as a culturally constructed element. Overall, by moving beyond current cognitive and linguistic theories and with the aim of analysing the relationship between language and cultural conceptualisations for describing embodied and culturally embedded phenomena such as humour, Cultural Linguistics (2017a, 2017b) provides coherent multidisciplinary analytical tools in the form of conceptual, analytical units such as cultural categories, cultural metaphors and cultural schemas, which are collectively called cultural conceptualisations, and that will be applied, for the first time, in this research, to Humour Studies.

Cultural conceptualisations, as Sharifian (2017a, 2017b) argues, capture all aspects of human life such as conceptualisations of life and death, to conceptualisations of emotion, body, and humour encoded and communicated through language features (Sharifian 2017a, 2017b). These language features are of particular importance for humour scholars and include culture-reliant humorous words, semantic and pragmatic meanings of humour, morpho-syntactic features of humour creation, and other language features like the use of specific dialects as a typical mechanism of creating humour, which may pose significant challenges in humorous discourse analysis.

Although humorous discourse seems to be ordinary or commonplace in everyday life, there is no unified or overarching definition of humour (Attardo 2014). Therefore, it is not surprising that defining humour is often challenging, and as Chiaro reminds us, "it may well be easier said than done" (2005: 135). However, bearing in mind that humour has communicational aspects (Scheel 2017), our operational definition of humour is: an aspect or an element of human communication and social interaction associated with the causes of amusement, whose perlocutionary effect is to amuse the audience (Banas et al. 2011; Martin 2007; Scheel 2017). More importantly, humour is 
also generally known to be deeply embedded in culture and consequently, for understanding humorous discourse, different types of cultural presuppositions are required (Stankic 2017; see also Athanasiadou 2017). Notwithstanding the fact that verbal humour is typically created by ambiguity or by playing with different levels of language structure (Chiaro 1992, 2018). For this reason, in order to understand a particular type of humour, humour scholars need to be aware of and unpack both the language and the cultural context to which that particular humour refers (Stankic 2017; see also Athanasiadou 2017).

What is of particular importance here is that (a) this cultural context underlying language features is shared by the members of a linguistic community collectively, and that (b) within a specific linguistic community, there are conventional and acceptable ways of saying things (Kecskes 2015: 114). Therefore, understanding humour depends deeply on its cultural specificity, in the sense of what is humorous within a specific culture (Antonopoulou 2004: 224). The explanation for this is connected to the fact that as Sharifian (2011: 5) maintains, language is deeply rooted in a group-level cognition that emerges from the interactions between members of a cultural group. Since language and culture are inseparable, intertwined and closely related, it is evident that language is one of the tools for storing and conveying cultural conceptualisations that emerge from the group-level cognition across time and space.

Considering verbal humour, it should be emphasised that "cultural conceptualisations mark not only humorous discourse itself in terms of different levels and units of language (e.g. speech acts, idioms, metaphors, grammar, etc.), but also language use and community practices (e.g. when it is (in)appropriate to joke and which form of humour to use in the given situation)" (Stankic 2017: 100; cf. Athanasiadou 2017). It should be noted that as Chiaro (2010) often argues, this type of humour is created to amuse different target groups that may not necessarily fit into a same linguistic and/or cultural community, as for example in the case of internationally best-selling humorous books published in the US for a global audience. Hence, the authors of this kind of humorous discourse for absorbing a broader audience should not only have in mind the perception of humour by the individual audience, but also the audience as a group. It is here that Cultural Linguistics plays a crucial role and accounts for this collective conceptualisation (Sharifian 2017a, 2017b). Human conceptualisation, as Sharifian (2017a: 2-4) argues, moves beyond the level of the individual mind, and therefore is collective at the level of a cultural group, and these collective cultural conceptualisations form cultural cognition. This collective characteristic of cultural conceptualisations is highly relevant to humour research, which is often overlooked in current linguistic and cognitive approaches to humour analysis, which tend to focus merely on the individual level of conceptualisations (Stankic 2017; see also Athanasiadou 2017). That is to say, for instance, in order to account for different types of humour - for example, ethnic humour or register humour - it is essential to take into account not only the individual level of conceptualisations but also the level of conceptualisations that is common to a cultural group (Stankic 2017: 100; see also Sharifian 2017a). Cultural conceptualisations are conceptual, analytical structures such as cultural categories, cultural metaphors and cultural schemas which exist not only at the individual level of cognition but also at the level of cultural group cognition negotiated across time and space within a cultural group (Sharifian 2017a, 2017b). Cultural categories, cultural metaphors and cultural schemas, the analytical tools of Cultural Linguistics (Sharifian 2017a, 2017b), will be discussed in the following sections before moving to the method of data analysis. 


\subsubsection{Cultural Categories}

Cultural categories are a class of cultural conceptualisations grounded in cultural cognition. They are culturally constructed conceptual categories that are reflected in the lexicon of human languages (Sharifian 2017a, 2017b). Cultural categories are rooted in people's cultural experiences (Xu \& Sharifian 2017) gained from their situatedness in a particular culture, and they mirror the structure of attributes perceived in the world which inevitably shape people's thoughts (Polzenhagen \& Xia 2014), such as emotion categories, event categories, colour categories, age categories, food categories, or kinship categories (Sharifian 2017a, 2017b).

\subsubsection{Cultural Metaphors}

Cultural metaphors are "cognitive structures that allow us to understand one conceptual domain in terms of another" (Sharifian 2013a: 1591). Cultural metaphors shape the way people think and act in intra-and-intercultural communication, and are categorised as fundamental to human thought and action (Sharifian 2015, 2017a, 2017b). For example, the cultural metaphor for marriage in Persian language and culture is "khāne-ye bakht" [literal translation: "house-of-fate"] (Sharifian \& Bagheri 2019), which refers to marriage, so in Persian cultural conceptualisations "Marriage Is Two Birds Coming Together To Make A Nest" is different conceptually from the English cultural metaphor "Marriage Is A Journey" (see also Sharifian \& Bagheri 2019), which should be taken into consideration in humorous discourse analysis for the audience's conceptualisation.

\subsubsection{Cultural Schemas}

The notion of cultural schema has a very high explanatory power to adequately explain its subject matter (Sharifian 2001, 2017a, 2017b; see also Strauss \& Quinn 1997). In general, schemas are "building blocks of cognition that help organise, interpret, and communicate information" (Sharifian, 2016b: 507). In particular, cultural schemas are a subclass of schemas that are shaped by culture and function as a foundation for communicating and interpreting cultural meanings (Sharifian 2001, 2017a, 2017b; see also Strauss \& Quinn 1997). They include event schemas, role schemas, image schemas, proposition schemas, or emotion schemas entrenched in cultural knowledge and experience, which are explained as the following:

1. Event schemas are "abstracted from our experience of certain events" (Sharifian 2011: 8), such as the event schema of the Persian Wedding Celebration.

2. Role schemas are "knowledge about social roles which denote sets of behaviours that are expected of people in particular social positions" (Sharifian 2011: 9), such as the role schema of a standup comedian.

3. Image schemas are "intermediate abstractions between mental images and abstract propositions that are readily imagined, perhaps as iconic images, and clearly related to physical or social experiences" (Sharifian 2011: 10), for example in a humorous utterance such as "he has gone off the rails," we are drawing on the image schema of the "path" to capture the conceptualisation of the domain of "thinking." The "path" image schema in this phrase shows the application of this image schema to the domain of "thinking" (cf. Sharifian 2011). 
4. Proposition schemas are "abstractions which act as models of thought and behaviour and specify concepts and the relations which hold among them," such as the Persian cultural conceptualisation of "khoshbakhti/happiness" as pre-destined fate (Sharifian 2011: 10; see also Sharifian \& Bagheri 2019).

5. Emotion schemas pave our way to "define, explain and understand emotions primarily by reference to the events and situations in which they occur" (Sharifian 2011: 11), such as the Persian cultural emotion schema of "khejalat," which is multilayered and overlaps with three different cultural emotion schemas in English, namely embarrassment, shyness and shame (Sharifian 2017a; Sharifian \& Bagheri 2019; see also section 7 for the application of these conceptual, analytical structures to the study's method of data analysis).

\section{Data}

Considering that this research focuses on humorous discourse, we selected humorous novels as the corpus for our analysis. Humorous novels reinforce the relation between linguistic elements and the cultural context in which they are produced (Rojo Lopez 2002; Chiaro 2010a, 2010b). They indicate the shared beliefs and culture common to the speakers of a linguistic community, their communicative norms and style; they are important cultural reference points to the societies in which they are produced (cf. Stankic 2017). The first humorous novel explored in the study is the bestselling book Funny in Farsi: A Memoir of Growing up Iranian in America. It is a humorous novel written by the American humorist Firoozeh Dumas, and was first published in English in New York by Random House in 2003. The second bestselling book, Daie Jan Napoleon [My Uncle Napoleon], is a humorous novel authored by Persian humorist Iraj Pezeshkzad. It was first published in Persian in Tehran by Random House publishing in 1973. The novels have a variety of mechanisms used to create humour, and they were well-received and widely read after being published.

\section{Data collection procedure}

The humorous instances have been identified and isolated in the data using the General Theory of Verbal Humour's Knowledge Recourses framework (see section 2.2 for a comprehensive discussion of the GTVH).

\section{Data analysis procedure}

Before proceeding to the method of data analysis in the next paragraphs, it seems necessary to discuss our understanding of context in this research. Context, as Martin (1995) discusses, is the mental contribution of the person who interprets an utterance. More precisely, it involves conceptual structures that are culturally constructed, and which exist in the speakers' mind (cf. Sharifian 2017a). It includes information from the physical environment and information that can 
be retrieved and inferred from our mental stores (see also Rojo Lopez 2002: 315). Language plays an important role here since it serves as a primary mechanism for storing and communicating conceptualisations that are culturally constructed, acting both as a memory bank and a fluid vehicle for the transmission of cultural conceptualisations underlying culturally constructed elements such as humour (Sharifian 2017a, 2017b). Humour, as Nash (1985:12) maintains, "characterises the interaction of persons in situations of cultures, and our response to it must be understood in that broad context" (see also Rojo Lopez 2002). Therefore, considering that the humorous instances in the corpus of this study are context-bound and typically not reusable without their culturalcontextual information, they will be interpreted within their relevant cultural context, contrary to single-joke-carrying texts which are typically reused in a wide range of settings regardeless of their relevant cultural-contextual information (Ritchie 2004; Abedinifard 2015, 2019), i.e. "Can you write shorthand? Yes, but it takes me longer" (Attardo 2002). For operationalising the method of data analysis explained in the next paragraphs, we have designed a table (see the next page). All the analysed data will be presented in a separate table like the following: 
The European Journal of Humour Research 8 (2)

Table 2. Humour analysis framework

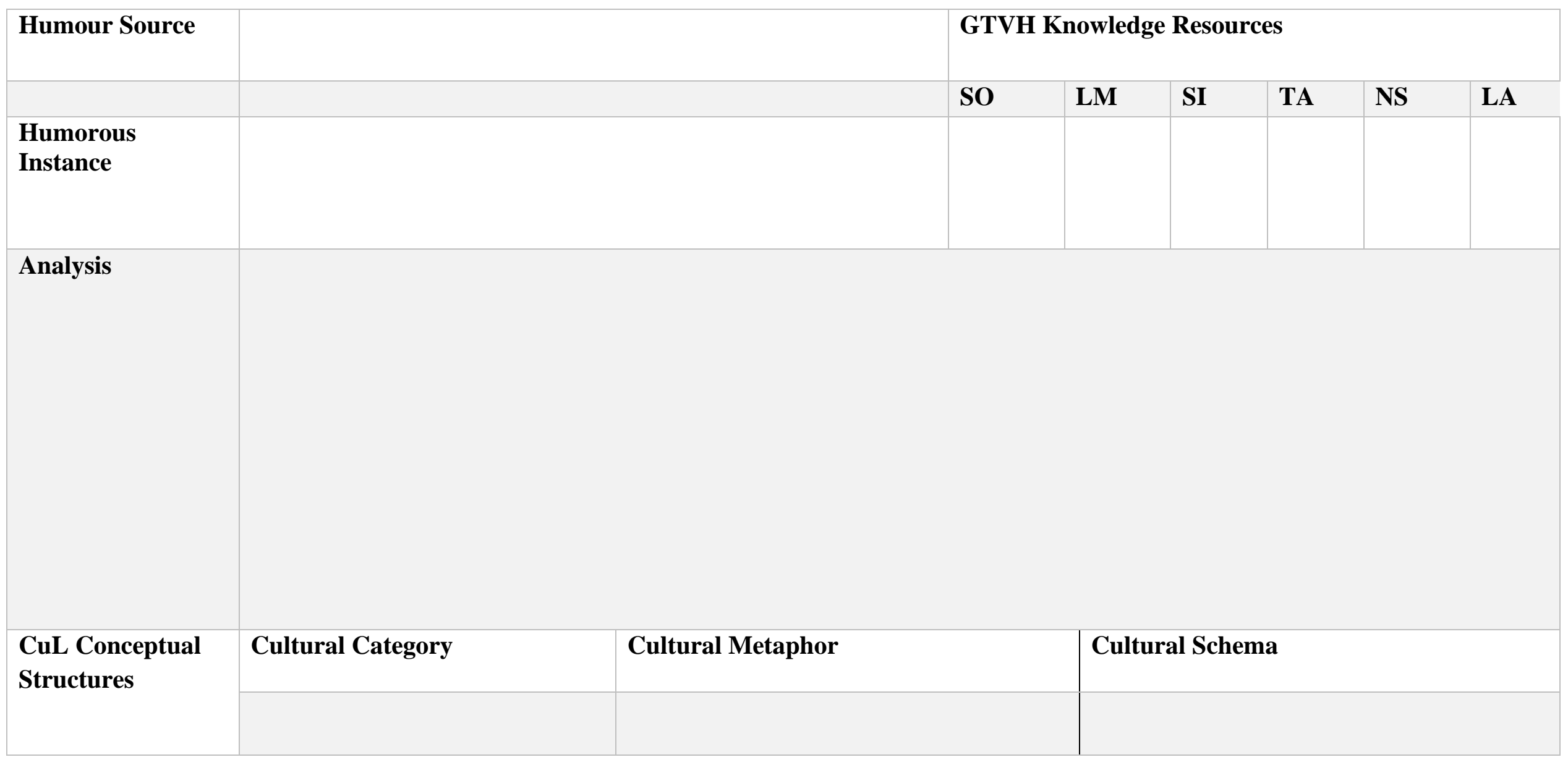


Humorous Instance in the humour analysis table indicates the instances of humour identified in the corpus. GTVH Knowledge Resources denotes the presence of each parameter of the General Theory of Verbal Humour framework in each example, and CuL Conceptual Structures signifies the Cultural Linguistics analytical structures instantiated in each case. The Analysis section entails the context-specific information about the events, objects and persons of the dialogues of the texts including the participants (their statuses and roles); action (the participants' action); and other relevant features of the context (the surrounding objects and events). The Analysis section also offers a textual as well as contextual analysis of the instances of humour detected in the texts applying the analytical framework of Cultural Linguistics which focuses on cultural schemas, cultural metaphors, and cultural categories activated in the mind of the readers. We discuss which cultural schemas, cultural metaphors, and cultural categories these humorous instances activate in the mind of readers, and the cultural values that are embedded in each particular humorous instance, which lead us to patterns and cultural conceptualisations underlying humour in the corpus.

\section{Towards a comprehensive theory of culturally constructed humour: contributions of cultural conceptualisations to the General Theory of Verbal Humour}

The data analysis was both quantitative and qualitative. Yet, for the purpose of this study, we focused, first and foremost, on the findings obtained from the qualitative analysis. Ninety-six humorous instances were detected and analysed in this research. Due to space limitations, only three examples, one for each analytical tool of cultural conceptualisations, i.e. cultural schemas, cultural metaphors, and cultural categories have been presented. Those interested in this research may contact the authors for the full version of the research. It is very much hoped that our proposal and the approach adopted in this study will prove to be useful in examining data from languages other than English and Persian, presented here, in moving towards a comprehensive theory of culturally constructed humour: 
Table 3. Example 1. Cultural category-based humour; cultural category of immigrants.

\begin{tabular}{|l|l|}
\hline Humour Source & Funny in Farsi \\
\hline $\begin{array}{l}\text { Humorous } \\
\text { Instance }\end{array}$ & $\begin{array}{l}\text { In America, I have an "ethnic" face, a certain immigrant look that says, "I'm } \\
\text { not Scandinavian."...in my next life, I am applying to come back as a Swede. } \\
\text { I assume that as a Swede, I will be a leggy blonde. Should God get things } \\
\text { confused and send me back as a Swede trapped in the body of a Middle } \\
\text { Eastern woman, I'll just pretend I'm French (Dumas, 2003: 37). }\end{array}$ \\
\hline
\end{tabular}

\title{
GTVH Knowledge Resources
}

\begin{tabular}{|c|c|c|c|c|c|}
\hline SO & $\mathbf{L M}$ & SI & $\mathbf{T A}$ & $\mathbf{N S}$ & $\mathbf{L A}$ \\
\hline $\begin{array}{l}\text { Swedish } \\
\text { Woman/ } \\
\text { Middle } \\
\text { Eastern. }\end{array}$ & $\begin{array}{l}\text { Role } \\
\text { Exchanges. }\end{array}$ & $\begin{array}{l}\text { Ethnic } \\
\text { Face. }\end{array}$ & $\begin{array}{l}\text { Prejudice } \\
\text { against } \\
\text { Persians. }\end{array}$ & $\begin{array}{l}\text { Simple } \\
\text { Narrative. }\end{array}$ & $\begin{array}{l}\text { English } \\
\text { Text. }\end{array}$ \\
\hline
\end{tabular}

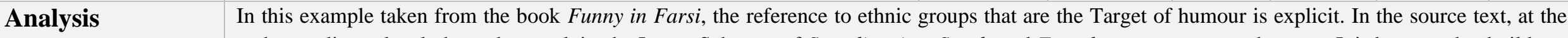
author-audience level, the author exploits the Image Schemas of Scandinavian, Swede and French women to create humour. It is humour that builds on stereotypes, based on the Script Opposition between the script for SWEDISH WOMAN vs. MIDDLE EASTERN WOMAN which is then reinforced in the punchline FRENCH WOMAN to mock the author's Persian ethnic difference in comparison with White Mainstream Americans, in particular, those of white, European heritage and the prejudice the author occasionally faces, alluding to how minority groups can be stereotyped in American culture. She uses the Image Schemas of Scandinavian, Swede and French to activate the cultural conceptualisation "ASSUMING ANOTHER RACE TO ALIGN WITH A MORE PRIVILEGED IDENTITY" that is shared among the speakers of American English to some extent. This conceptualisation marks a genre dominant in many forms of ethnic - American literature — the Passing Narrative — which has historically discussed the concept of presuming another race, religion or class to associate with a more privileged identity in American culture (Boggs 2010; Pazargadi 2012) and is exploited to create humour in this example. In this case, the author uses humour to ridicule the monolithic views about Iranians in the US (Pazargadi 2012).
\end{abstract}

\begin{tabular}{|c|c|c|c|}
\hline \multirow{2}{*}{$\begin{array}{l}\text { CuL Conceptual } \\
\text { Structures }\end{array}$} & Cultural Category & Cultural Metaphor & Cultural Schema \\
\hline & $\begin{array}{l}\text { Cultural Category of Persian } \\
\text { Immigrants. }\end{array}$ & $\mathrm{No}^{1}$ & Cultural Image Schema of Ethnic Face. \\
\hline
\end{tabular}

\footnotetext{
${ }^{1}$ In this example, the reference to an ethnic group is the Target of humour and the author exploits the Image Schemas of Scandinavian, Swede and French women to create humour. It is humour that builds on stereotypes; thus, it is categorised as the Cultural Image Schema of Ethnic Face. No instance of Cultural Metaphor is found in this excerpt.
} 
Table 4. Example 2. Cultural schema-based humour: cultural schema of "Taarof."

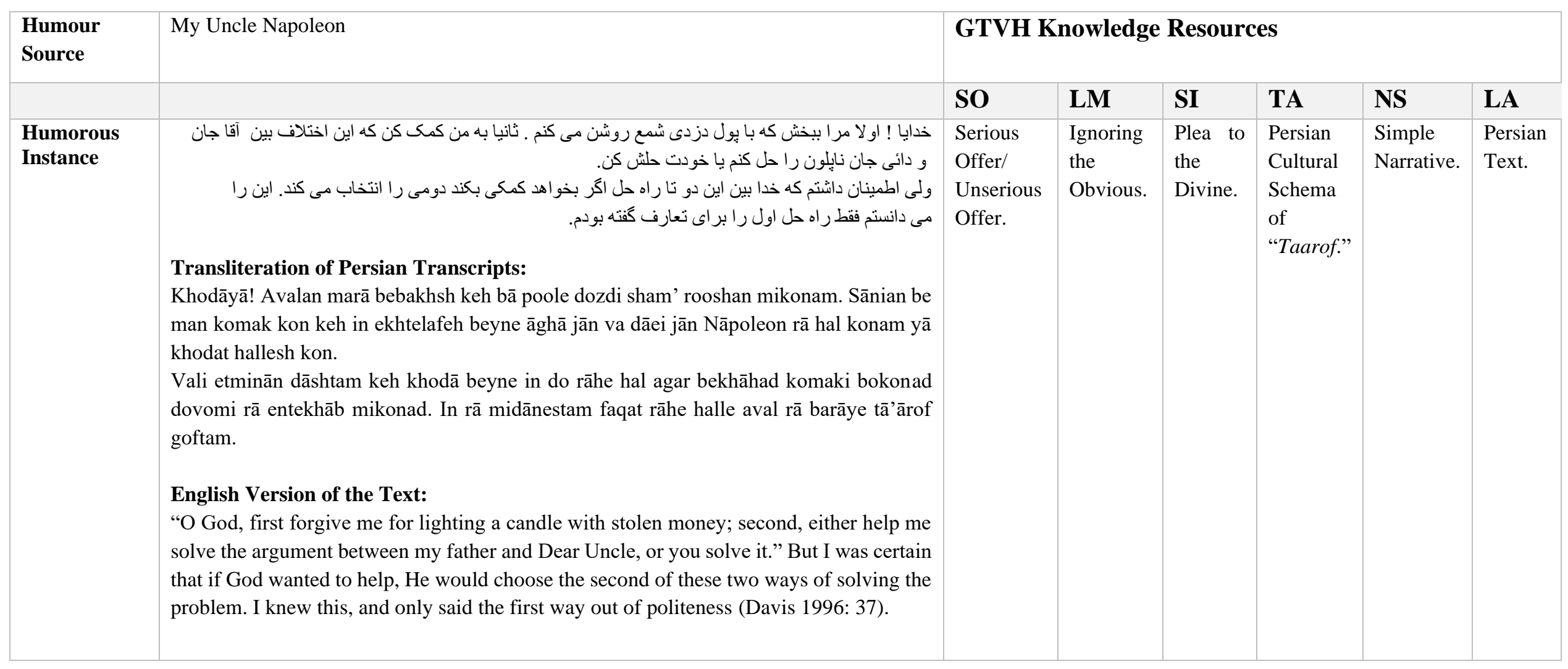


In this example taken from the novel My Uncle Napoleon, the humorous reference to the Persian Cultural Schema of "taarof" (Sharifian 2011, 2013a; 2016a; see below) and a common Persian suspiciousness of foreigners, particularly the British (Rahimieh 2011; see below) are the Targets of humour. In the source text, at the author-audience level, the author exploits the Persian Cultural Schema of "taarof" to create humour and provoke witty thought. It is humour that builds on the Cultural Schema of "taarof," based on the Script Opposition between the script for SERIOUS OFFER OF HELP TO SOLVE AN ARGUMENT vs. UNSERIOUS OFFER OF HELP TO SOLVE AN ARGUMENT which is then reinforced in the humour's punchline by using the meta-pragmatic comment ONLY SAID THE FIRST WAY OUT OF POLITENESS [IT WASN'T A SERIOUS OFFER/ IT WAS JUST OUT OF TAAROF].

"Taarof," which has been used in this excerpt to create humour, denotes "compliment(s)," "ceremony," "offer," "courtesy," "flattery" in Persian language and culture (Aryanpur Kashani \& Aryanpur Kashani 1984: 226; see also Sharifian 2013: 99); it has no direct equivalence in English language and culture. And Uncle Napoleon, so called by his nieces and nephews behind his back, refers to a caricatured lower-ranking officer character in the novel, who is so obsessed with the personality of Napoleon that, behind his back, his folks humorously call him Dear Uncle Napoleon (cf. Rahimieh 2011). Uncle Napoleon captures a widespread Persians Cultural Conceptualisation that "THE BRITISH ARE BEHIND ALL IMPORTANT AFFAIRS IN THEIR COUNTRY" (Rahimieh 2011: 597). Uncle Napoleon is a Cultural Metaphor for the conspiracy theorists, Persians' fascination with conspiracy theories, and the suspicion of the British that gave rise to "Napoleonism" among Persians, reflecting general suspiciousness of foreigners in Persian culture (Rahimieh 2011).

Regarding the role of the Persian Cultural Schema of "taarof' (Pourmohammadi 2018) in creating humour in this excerpt, as mentioned above, according to the General Theory of Verbal Humour's metrics, it is humour based on Script Opposition between the script for Serious Offer vs. Unserious Offer (Actual/Non-Actual situations, see below). In general, "taarof" has been translated into English as "etiquette," "ritual politeness," etc. (Sharifian 2016a), but none of these notions really captures what this Cultural Schema is. "Taarof" underlies a wide variety of speech acts in Persian language and culture. For instance, it underlies the speech acts of "offering goods and services" (Sharifian 2016a; see also Sharifian \& Bagheri 2019). Hence, that is the underlying Cultural Schema, which is called "taarof" in the Persian language and culture. Then, in the next layer, "taarof" got associated with a speech act of "offering services" (Sharifian 2016a), e.g. when you offer your help to someone. For instance, in this excerpt, the narrator is humorously offering to help solve an argument between his father and Dear Uncle Napoleon, out of "taarof."

That particular speech act, then, got associated with a number of pragmatic units (Sharifian 2016a). Therefore, one of the pragmatic units, that for example, the speech act of "offering services," such as "help someone solve an argument" associated with "taarof," conjures up in the mind of Persian language-and-culture-audience, is "insist on the offer for several turns" (Sharifian 2016a). Hence, the underlying Cultural Schema is broad and is associated with a number of speech acts; one of the speech acts in this humorous utterance is "offering services," such as "help someone solve an argument," and then, one of the pragmatic units associated with this speech act, activated in the mind of Persian language-and-culture-audience is "insist on the offer for several turns," which is a very common norm in Persian culture. Lastly, the actual linguistic realisation of this can again be in several different formats (Sharifian 2016a). One of them activated in the mind of Persian language-and-culture-audience is "please help me," which creates humour in this example. The interlocutor insists on this several times, and the other person refuses that several times, out of what in Persian culture is called "taarof," until he/she eventually accepts it (Sharifian 2016a; see also Pourmohammadi 2018). Overall, the Cultural Linguistics framework is capable of capturing Cultural Schemas, and of unpacking such a relationship between Cultural Schemas, their speech acts, their associated pragmatic units, and their actual linguistic realisations for humour scholars, and it empowers them to appropriately analyse humour, for adequate conceptualisations of the target audience.

$\mathrm{CuL}$

Conceptual

Structures

\begin{tabular}{|l|l|}
\hline Cultural Category & Cultural Metaphor \\
\hline No. & Cultural Metaphor of "Napoleonism."2 \\
\hline
\end{tabular}

\section{Cultural Schema}

Persian Cultural Schema of "Taarof."

${ }^{2}$ Uncle Napoleon, a caricatured character, is a retired low-rank officer of Persian gendarmerie in the novel, taking off from the common belief among Persians that the British are behind every important thing in their country (Rahimieh, 2011). The character humorously starts to exaggerate his own minor role in helping the Persian gendarmerie to suppress local rebels, making it appear that his service was part of the bigger Persian battle against British imperial powers during World 
Table 5. Example 3. Cultural metaphor-based humour; cultural metaphor of Iran as land of Persian cats.

\begin{tabular}{|c|c|c|c|c|c|c|c|c|}
\hline Humour & \multicolumn{2}{|l|}{ Funny in Farsi } & \multicolumn{6}{|c|}{ GTVH Knowledge Resources } \\
\hline & & & SO & $\mathbf{L M}$ & SI & TA & NS & $\mathbf{L A}$ \\
\hline $\begin{array}{l}\text { Humorous } \\
\text { Instance }\end{array}$ & \multicolumn{2}{|c|}{$\begin{array}{l}\text { That was news to us; the only cats we had ever seen back home were the mangy } \\
\text { strays that ate scraps behind people's houses. From that day, when I told people I } \\
\text { was from Iran, I added 'where Persian cats come from.' That impressed them } \\
\text { (Dumas 2003: 33). }\end{array}$} & $\begin{array}{l}\text { Fierce Alley } \\
\text { Cats/Fancy } \\
\text { Expensive Pets. }\end{array}$ & $\begin{array}{l}\text { Reasoning } \\
\text { from False } \\
\text { Premises. }\end{array}$ & $\begin{array}{l}\text { Persian } \\
\text { Cats. }\end{array}$ & $\begin{array}{l}\text { Mistaken } \\
\text { Image of } \\
\text { Iran. }\end{array}$ & $\begin{array}{l}\text { Simple } \\
\text { Narrative. }\end{array}$ & $\begin{array}{l}\text { English } \\
\text { Text. }\end{array}$ \\
\hline Analysis & \multicolumn{8}{|c|}{$\begin{array}{l}\text { In this passage from Funny in Farsi, the reference to Anglo-Americans' mistaken image of Iran is the Target of humour (see below). In the source text, at the } \\
\text { author-audience level, the author exploits the Cultural Image Schemas of Persian cats to create humour and witty thought. It is humour based on the Script } \\
\text { Opposition between the script for MANGY STRAYS THAT ATE SCRAPS BEHIND PEOPLE'S HOUSES and FANCY EXPENSIVE PETS, which mocks } \\
\text { the Anglo-Americans' mistaken image of Iran, and alludes to the hostility Iranians experience in Anglo-American societies (Behdad 2005; Behdad \& Thomas } \\
\text { 2014). The author uses the Cultural Image Schemas of Persian Cats to activate the Cultural Conceptualisation that "PERSIANS OFTEN EXPLAIN THEIR } \\
\text { CULTURE AND IDENTITY USING THEIR HOST CULTURE'S TERMS, TO NEUTRALISE THE NEGATIVE REACTIONS TOWARDS THEM, } \\
\text { WITH THE MORE POSITIVE, ALBEIT INCORRECT METAPHORS" (see also Behdad 2005; Pazargadi 2012). After the 1980s Hostage Crisis and the } \\
\text { US Embassy Takeover in Iran, the identity of Iranians has been rendered ethnically pejorative, and they have experienced hostility toward themselves (Behdad } \\
\text { 2005; Behdad \& Thomas 2014; Ashouri Talooki 2017). This creates a critical era for Persian immigrants, who have desired assimilation into their host culture. } \\
\text { In an effort to promote a less-threatening Cultural Image Schema of Iranians to Anglo-Americans, the author and her family use the Cultural Schema of Persian } \\
\text { Cats as a means to neutralise the negative reactions towards Iranians, with the more positive, albeit incorrect metaphors, which create humour in this example } \\
\text { (Behdad 2005; Pazargadi 2012; Behdad \& Thomas 2014). Overall, this example includes the cultural Image Schema of Persian cats, which conjures up the } \\
\text { Anglo-American Conceptualisation of cats as "FANCY EXPENSIVE PETS, AND A HOBBY INVOLVING THE APPRECIATION OF DOMESTIC } \\
\text { ANIMALS"(Pazargadi 2012), however, for Iranian readers, Persian Cats activate the Iranians' Conceptualisation of cats as "MANGY FIERCE ALLEY CATS } \\
\text { THAT ATE SCRAPS BEHIND PEOPLE'S HOUSES," which is the origin of the humour in this example. }\end{array}$} \\
\hline \multirow{2}{*}{$\begin{array}{l}\text { CuL } \\
\text { Conceptual } \\
\text { Structures }\end{array}$} & Cultural Category & \multicolumn{2}{|l|}{ Cultural Metaphor } & \multicolumn{5}{|c|}{ Cultural Schema } \\
\hline & No. & \multicolumn{2}{|c|}{$\begin{array}{l}\text { Cultural Metaphor of Iran as Land of Persian } \\
\text { Cats. }\end{array}$} & \multicolumn{5}{|c|}{ Cultural Image Schema of Persian Cats. } \\
\hline
\end{tabular}

War II. In his memoirs, which he frequently exposes his acquaintances to, it is humorous that he uplifts the insurgents to British agents and associates himself with Napoleon (Rahimieh, 2011). 


\section{Discussion and concluding remarks}

The analysis of the data indicates that the General Theory of Verbal Humour, for all its breadth, falls short of accounting for culturally constructed verbal humour. We contend that downplaying humour analysis to just linguistic formalisms, such as the ones proposed in the Semantic Script Theory of Humour and the General Theory of Verbal Humour, is inadequate, as these linguistic-oriented approaches need to be reinforced, at underlying conceptual layers of the analysis, by the cutting-edge, recently developed framework: Cultural Linguistics' cultural conceptualisations analytical framework, to adequately account for this complex culture-reliant phenomenon. Overall, several other humour studies have come to conclusions relevant to ours: that the General Theory of Verbal Humour cannot capture the culturalcontextual factors in humour analysis (see Stankic 2017, among others). However, what we propose in the present study, is a new systematic analytical framework, from the metatheoretical point of view, for an in-depth analysis of verbal humour - despite its notorious elusiveness - as an analytical concept in humour research. We argue that humour is rooted in the specific relationship between language and culture, which attracts the attention of many scholars (cf. Athanasiadou 2017; Stankic 2017). These scholars who have been interested in exploring the relationship between language and culture exemplified in humour have faced as at least two significant challenges regarding the notion of culture: (1) its abstractness and (2) the various multifaceted, multi-layered assumptions often associated with it (see Sharifian 2015, 2017a, 2017b). As Sharifian, the anthropological linguistics professor from Monash University, Melbourne (2017a, 2017b) argues, although humour scholars have had rigorous tools at their disposal, what has not been available to them is an analytical model for breaking down cultures and examining their components (Sharifian 2015, 2017a, 2017b), so that the interplay of culturally constructed dimensions underlying humour could be explored across different languages and cultures for adequate conceptualisations of the audience; a significant step in Humour Studies, that the present research attempted to take, in moving towards a comprehensive theory of culturally constructed humour.

\section{Acknowledgements}

We would like to thank Professor Villy Tsakona and the anonymous reviewers for their constructive feedback on the earlier versions of this paper.

\section{References}

Abedinifard, M. (2015). Humour and Gender Hegemony: The Panoptical Role of Ridicule visà-vis Gender. Alberta: University of Alberta, $\mathrm{PhD}$ thesis.

Abedinifard, M. (2019). 'Persian 'rashti jokes': Modern Iran's palimpsests of gheyrat-based masculinity'. British Journal of Middle Eastern Studies 46 (4), pp. 564-582.

Antonopoulou, E. (2004). 'Humour theory and translation research: Proper names in humorous discourse'. Humour: International Journal of Humour Research 17 (3), pp. 219-256.

Aryanpur Kashani, A., \& Aryanpur Kashani, M. (1984). Aryanpur Persian-English Dictionary. Teharn: Amir-Kabir Publications.

Ashouri Talooki, R. (2017). Let Me Tell You What It Means: Reading beyond Humor in Selected Iranian-American Memoirs, Stand-up Comedy, and Film in the Post-9/11 Era. Ontario: The University of Western Ontario, PhD thesis. 
Athanasiadou, A. (2017). 'Cultural conceptualisations of irony in Greek', in Sharifian, F. (ed.), Advances in Cultural Linguistics, Singapore: Springer, pp. 111-124.

Attardo, S. (1994). Linguistic Theories of Humour. Berlin/New York: Mouton de Gruyter.

Attardo, S. (1997). 'The semantic foundations of cognitive theories of humour'. Humour: International Journal of Humour Research 10 (4), pp. 395-420.

Attardo, S. (2001). Humorous Texts: A Semantic and Pragmatic Analysis. Berlin/New York: De Gruyter Mouton.

Attardo, S. (2002). 'Translation and humour: An approach based on the General Theory of Verbal Humour (GTVH)'. The Translator 8 (2), pp. 173-194.

Attardo, S. (2003). 'Introduction: The pragmatics of humour'. Journal of Pragmatics 35 (9), pp. 1287-1294.

Attardo, S. (2008). 'A primer for the linguistics of humour', in Raskin, V. (ed), The Primer of Humour Research. Berlin: De Gruyter Mouton, pp. 101-155.

Attardo, S. (2014). 'Humour content versus structure', in Attardo, S. (ed.), Encyclopedia of Humour Studies, Thousand Oaks: Sage, pp. 355-355.

Attardo, S. (2014). 'Metaphor', in S. Attardo (ed.), Encyclopedia of Humour Studies, Thousand Oaks: Sage, pp. 505-506.

Attardo, S. (2017a). 'The General Theory of Verbal Humour', in Attardo, S. (ed.), The Routledge Handbook of Language and Humour, London: Routledge, pp. 126-142.

Attardo, S. (2017b). 'The GTVH and humorous discourse', in Chlopicki, W. \& Brzozowska, D. (eds.), Humorous Discourse, Berlin/Boston: De Gruyter Mouton, pp. 93-107.

Attardo, S. (ed.) (2017c). The Routledge Handbook of Language and Humour. London: Routledge.

Attardo, S., Hempelmann, C. F. \& Di Maio, S. (2002). 'Script oppositions and logical mechanisms: Modeling incongruities and their resolutions'. Humour: International Journal of Humour Research 15 (1), pp. 3-46.

Attardo, S., \& Raskin, V. (1991). 'Script theory revis(it)ed: Joke similarity and joke representation model'. Humour: International Journal of Humour Research 4 (3-4), pp. 293 348.

Attardo, S., \& Raskin, V. (2017). 'Linguistics and humour theory', in Attardo, S. (ed.), The Routledge Handbook of Language and Humour, London: Routledge, pp. 49-63.

Banas, J. A., Dunbar, N., Rodriguez, D. \& Liu, S.-J. (2011). 'A review of humour in educational settings: Four decades of research'. Communication Education, 60 (1), pp. 115-144.

Behdad, A. (2005). A Forgetful Nation: On Immigration and Cultural Identity in the United States. Durham: Duke University Press.

Behdad, A., \& Thomas, D. (2014). A Companion to Comparative Literature. Hoboken, New Jersey: John Wiley \& Sons.

Berger, A. A. (1987). 'Humour: An introduction'. American Behavioural Scientist, 30 (3), pp. 615.

Berger, A. A. (2014). 'Targets of humour', in S. Attardo (ed.), Encyclopedia of Humour Studies, Thousand Oaks: Sage, pp. 753-755.

Berger, A. A. (2017). An Anatomy of Humour. London: Routledge.

Boggs, C. G. (2010). Transnationalism and American Literature: Literary Translation 17731892. London: Routledge.

Brekhus, W., \& Ignatow, G. (2019). The Oxford Handbook of Cognitive Sociology. Oxford: Oxford University Press.

Chiaro, D. (1992). The Language of Jokes. Analyzing Verbal Play. London: Routledge.

Chiaro, D. (2005). 'Foreword. Verbally expressed humour and translation: An overview of a neglected field'. Humour: International Journal of Humour Research 18 (2), pp. 135-146. 
Chiaro, D. (ed.) (2010). Translation, Humour and Literature: Translation and Humour (Vol. 1). London: Bloomsbury Publishing.

Chiaro, D. (2018). The Language of Jokes in the Digital Age. New York: Routledge.

Chlopicki, W. (2017). 'Humour and narrative', in Attardo, S. (ed.), The Routledge Handbook of Language and Humour, London: Routledge, pp. 143-157.

Chlopicki, W. \& Brzozowska, D. (2017). 'A foreword on humorous discourse', in Chlopicki, W. \& Brzozowska, D. (eds.), Humorous Discourse (Humour Research series vol. 11), Berlin/Boston: De Gruyter Mouton, pp. 1-10.

Chovanec, J., \& Tsakona, V. (2018). 'Investigating the dynamics of humour: Towards a theory of interactional humour', in Chovanec, J., \& Tsakona, V. (eds), The Dynamics of Interactional Humour: Creating and Negotiating Humour in Everyday Encounters (Vol. 7), Amsterdam: John Benjamins, pp. 1-28.

Davis, D. (1996). My Uncle Napoleon (a novel by Iraj Pezeshkzad translated by Dick Davis). Maryland: Mage Publishers.

Dumas, F. (2003). Funny in Farsi: A Memoir of Growing up Iranian in America. New York: Random House.

Ermida, I. (2008). The Language of Comic Narratives: Humour Construction in Short Stories (Humour Research series vol. 9). Berlin/Boston: De Gruyter Mouton.

Giora, R. (1991). 'On the cognitive aspects of the joke'. Journal of Pragmatics 16 (5), pp. 465 485.

Giora, R. \& Attardo, S. (2014). 'Irony', in Attardo, S. (ed.), Encyclopedia of Humour Studies, Thousand Oaks: Sage, pp. 398-402.

Kecskes, I. (2015). 'Intracultural communication and intercultural communication: Are they different?', International Review of Pragmatics 7 (2), pp. 171-194.

Krikmann, A. (2006). 'Contemporary linguistic theories of humour'. Folklore: Electronic Journal of Folklore 33, pp. 27-58.

Lakoff, G. (1987). 'The death of dead metaphor'. Metaphor and Symbol 2 (2), pp. 143-147.

Martin, R. A. (2007). The Psychology of Humour: An Integrative Approach. London: Elsevier.

Martín, R. M. (1995). Lingüistica Para Traducir [Linguistics for Translation]. Barcelona: PURESA Publications.

Morreall, J. (1997). Humour Works. Amherst, Ohio: Human Resource Development Press.

Mulder, M. P., \& Nijholt, A. (2002). Humour Research: State of the Art. Enschede, Netherlands: Centre for Telematics and Information Technology, University of Twente Press.

Nash, W. (1985). The Language of Humour. London/New York: Longman.

Olin, L. (2016). 'Questions for a theory of humour'. Philosophy Compass 11 (6), pp. 338-350.

Pazargadi, L. (2012). Mosaics of Identity: Reading Muslim Women's Memoirs from Across the Diaspora. Los Angeles: University of California, $\mathrm{PhD}$ thesis.

Peeters, B. (2016). 'Applied ethnolinguistics', International Journal of Language and Culture 3 (2), pp. 137-160.

Polzenhagen, F., \& Xia, X. (2014). 'Language, culture, and prototypicality', in Sharifian, F. (ed.), The Routledge Handbook of Language and Culture, London: Routledge, pp. 269-285.

Pourmohammadi, E. (2018). The Use of "Taarof": The Generation and Gender Factors in Iranian Politeness System. Saskatchewan: University of Saskatchewan, PhD thesis.

Rahimieh, N. (2011). 'Dā̄ jān nāpelon (uncle napoleon)', in Yarshater, E. (ed.), Encyclopaedia Iranica, New York: Columbia University Center for Iranian Studies, p. 597.

Raskin, V. (1985). Semantic Mechanisms of Humour. Dordrecht: Reidel.

Raskin, V. (ed.) (2008). The Primer of Humour Research (Humour Research series vol. 8). Berlin/Boston: Walter de Gruyter. 
Raskin, V. (2017). 'Script-based semantic and ontological semantic theories of humour', in Attardo, S. (ed.), The Routledge Handbook of Language and Humour, London: Routledge, pp. 109-125.

Ritchie, G. (2004). The Linguistic Analysis of Jokes. London: Routledge.

Rojo Lopez, A. M. (2002). 'Applying frame semantics to translation: A practical example'. Meta: Translators' Journal 47 (3), pp. 312-350.

Scheel, T. (2017). 'Definitions, theories, and measurement of humour', in Scheel, T., \& Gockel, C. (eds.), Humour at Work in Teams, Leadership, Negotiations, Learning and Health, New York: Springer, pp. 9-29.

Sharifian, F. (2003). 'On cultural conceptualisations'. Journal of Cognition and Culture 3 (3), pp. 187-207.

Sharifian, F. (2011). Cultural Conceptualisations and Language: Theoretical Framework and Applications (Vol. 1). Amsterdam: John Benjamins.

Sharifian, F. (2012). 'Translation and body-part terms: The case of cheshm 'eye' in Persian'. Journal of Language, Culture, and Translation, 1(1), pp. 1-16.

Sharifian, F. (2013a). 'Cultural linguistics and intercultural communication', in Sharifian, F., \& Jamarani, M. (eds.), Language and Intercultural Communication in the New Era, London: Routledge, pp. 74-94.

Sharifian, F. (2015). 'Cultural linguistics: The development of a multidisciplinary paradigm'. Language and Semiotic Studies, 1(1), pp. 1-26.

Sharifian, F. (2016a). 'Cultural linguistics and translation: The case of xoshbaxti ('happiness/prosperity') and baxt ('fate/luck') in Persian'. Retrieved from https://www.youtube.com/watch?v=op-PzIgZwWo.

Sharifian, F. (2016b). 'Cultural pragmatic schemas, pragmemes, and practs: A Cultural linguistics perspective', in Allan, K., Capone, A., \& Kecskes, I. (eds.), Pragmemes and Theories of Language Use, New York: Springer, pp. 505-519.

Sharifian, F. (2017a). Cultural Linguistics: Cultural Conceptualisations and Language (Vol. 8). Amsterdam: John Benjamins.

Sharifian, F. (2017b). 'Cultural linguistics: The state of the art', in Sharifian, F. (ed.), Advances in Cultural Linguistics, New York: Springer, pp. 13-28.

Sharifian, F. (2018). 'Metacultural competence in English language teaching (ELT)', in Liontas, J. I. (ed.), The TESOL Encyclopedia of English Language Teaching, Hoboken, New Jersey: John Wiley \& Sons, pp. 1-6.

Sharifian, F., \& Bagheri, M. (2019). 'Conceptualisations of xoshbaxti ('happiness/prosperity') and baxt ('fate/luck') in Persian'. Journal of Historical Pragmatics 20 (1), pp. 78-95.

Stankic, D. P. (2017). 'Cultural conceptualisations in humorous discourse in English and Serbian', in Sharifian, F. (ed.), Advances in Cultural Linguistics, New York: Springer, pp. $29-48$.

Strandell, J. (2019). 'Bridging the vocabularies of dual-process models of culture and cognition', in Brekhus, W. H., \& Ignatow, G. (eds.), The Oxford Handbook of Cognitive Sociology, Oxford: Oxford University Press, pp. 192-286.

Strauss, C., \& Quinn, N. (1997). A Cognitive Theory of Cultural Meaning (Vol. 9). Cambridge: Cambridge University Press.

$\mathrm{Xu}, \mathrm{Z} ., \quad \&$ Sharifian, F. (2017). 'Unpacking cultural conceptualisations in Chinese English'. Journal of Asian Pacific Communication 27 (1), pp. 65-84.

$\mathrm{Yu}$, N. (2007). 'The Chinese conceptualisation of the heart and its cultural context', in Sharifian, F., \& Palmer, G. B. (eds.), Applied Cultural Linguistics: Implications for Second Language Learning and Intercultural Communication (Vol. 7), Amsterdam: John Benjamins, pp. 6585. 
Zabalbeascoa, P. (2019). That's Just What We Need, a Fourth Language. Multilingual Humour in Film and Television Translation. Madrid: The Spanish Ministry of Economy and Competitiveness Press. 